\title{
História, nação e raça no contexto da Exposição do Centenário em 1922
}

\section{History, nation and race in the context of the Centennial Exhibition of 1922}

\author{
Sven Schuster \\ Professor da Escuela de Ciencias Humanas/ \\ Universidad del Rosario. \\ Calle 12C, 6-25; Edificio Santafé, of. 512 \\ Bogotá - Colômbia \\ schuster.svenb@urosario.edu.co
}

SCHUSTER, Sven. História, nação e raça no contexto da Exposição do Centenário em 1922. História, Ciências, Saúde Manguinhos, Rio de Janeiro. Disponível em: http://www.scielo.br/hcsm.

\section{Resumo}

Tem como tema os debates públicos e acadêmicos sobre a história do Brasil que ocorreram no contexto da Exposição do Centenário, em 1922, na cidade do Rio de Janeiro. Pretende-se destacar a maneira como certos conceitos sobre 'nação' e 'raça' foram debatidos em conferências acadêmicas sobre história, antropologia e arqueologia, como foram conectados à história nacional e como se tornaram, finalmente, parte da autoimagem nacional. Além disso, o artigo indaga como e por quem esses ideais foram contestados.

Palavras-chave: Exposição do Centenário; história; raça; conferências acadêmicas; Brasil.

\section{Abstract}

The subjects addressed in this article are the public and academic debates about the history of Brazil that took place in the context of the Centennial Exhibition held in 1922 in the city of Rio de Janeiro. The aim is to highlight how certain concepts of nation and race were debated in academic discussions about history, anthropology and archaeology, how they were related to the nation's history, and how they ultimately became a part of the nation's self-image. Furthermore, the article investigates how and by whom these ideals were contested.

Keywords: Centennial Exhibition; history; race; academic discourse; Brazil. 
Le ogo após o grande sucesso da Exposição Nacional de 1908, por meio da qual a elite política e cultural da Primeira República comemorou os cem anos da vinda da família real, fato interpretado como o primeiro passo para a Independência, o governo decidiu organizar uma exposição ainda maior para celebrar a mais sagrada data do calendário nacional: o dia 7 de setembro de 1822, ou seja, o dia em que dom Pedro I supostamente teria pronunciado sua famosa frase "Independência ou morte", selando assim a separação entre ele e a pátria mãe. A Exposição do Centenário, realizada no Rio de Janeiro entre setembro de 1922 e julho de 1923, durante a presidência de Epitácio Pessoa (1919-1922), foi um verdadeiro sucesso, atraindo mais de três milhões de visitantes e vários expositores estrangeiros.

Embora as despesas tenham sido grandes, como nota Mauricio Tenório-Trillo (1998), os gastos se justificaram na opinião dos organizadores do evento. Segundo eles, a exposição foi uma ocasião única para apresentar o Brasil ao mundo como um país moderno e que se considerava, parcialmente, no caminho da industrialização. Para isso contava com um grande número de imigrantes europeus, que o teriam transformado em um lugar mais 'civilizado', ou de melhores 'qualidades raciais'.

Outro enfoque da exposição foram as reformas urbanas realizadas durante e depois do governo do prefeito Francisco Pereira Passos (1902-1906), o qual tinha transformado o Rio de Janeiro na 'cidade maravilhosa', uma espécie de Paris tropical (Benchimol, 1990). Aquela que fora conhecida no mundo como a 'cidade da morte' - devido às frequentes epidemias de febre amarela - luzia agora com prédios representativos, parques, avenidas e infraestrutura moderna. Como nas exposições do século XIX, as encenações de conceitos, tais como, 'progresso', 'civilização' e 'raça' formaram os eixos temáticos da Exposição do Centenário, apesar de algumas mudanças discursivas nos modos de conceber esses conceitos, sobre as quais tratarei neste ensaio.

O artigo não pretende indagar sobre o evento em si, ou seja, as exposições temáticas, os objetos expostos, os pavilhões nacionais, mas, sim, sobre os debates públicos e acadêmicos acerca do sentido da história que ocorreram em seu contexto. Para isso, mostra a maneira como tais conceitos, especialmente os que se referem à 'raça', foram conectados à história do Brasil e como se tornaram parte da autoimagem nacional. Além disso, o ensaio discute como e por quem esses conceitos foram contestados. Nesse sentido, as fontes básicas deste trabalho foram as atas dos congressos de história, arqueologia e antropologia que ocorreram antes e durante a exposição, algumas publicações comemorativas da Independência, assim como a representativa imprensa carioca dos anos 1920.

\section{História e discurso racial em 1922: a perspectiva oficialista}

Os congressos que aconteceram no Rio de Janeiro em 1922 não só nos oferecem uma perspectiva nacional sobre a maneira como a elite política e cultural queria dotar de sentido a história do Brasil, mas também foram espaços transnacionais nos quais houve um rico intercâmbio entre acadêmicos latino-americanos, europeus e norte-americanos. A diversidade dos participantes dos congressos explica em parte o porquê de alguns deles não concordarem com a linha oficialista de apresentação da sociedade brasileira como resultado de um longo processo teleológico para o progresso e a civilização, cuja culminação seria a República federal. 
Ao contrário, muitas das palestras, do mesmo modo que alguns comentários na imprensa sobre a interpretação da história do Brasil, espelharam a situação de crise na qual o país estava submerso no início dos anos $1920 .^{1}$

Visto a partir de uma perspectiva atual, o ano de 1922 marcou uma verdadeira ruptura na história nacional, embora a queda do regime republicano só viesse a ocorrer oito anos depois. Naquele ano, importantes setores da sociedade começaram a questionar abertamente o funcionamento do Estado oligárquico, e, para isso, aproveitaram a crescente atenção midiática estimulada pelo centenário. Segundo tais grupos, o Estado não teria feito o suficiente para garantir uma distribuição equitativa dos lucros provindos do setor cafeeiro. Além disso, a elite política tradicional nunca teria possuído uma visão do país como um todo, mas apenas de algumas cidades do litoral. No interior empobrecido, no entanto, ainda faltavam infraestrutura, indústrias modernas, saúde, educação, segurança e assistência social. Nesse momento, o governo se viu confrontado com uma série de demandas da ascendente classe média urbana, dos operários organizados e da 'contraelite' intelectual, que denunciou com veemência o estilo autocrático e a corrupção da casta política tradicional.

Sobretudo na São Paulo e no Rio de Janeiro dos conturbados anos 1920, houve greves e protestos que indicaram o nível de descontentamento nas camadas médias e baixas. Alguns intelectuais paulistas chegaram inclusive à conclusão de que o Rio de Janeiro, sendo o centro das decisões políticas da Primeira República, não representaria o "verdadeiro Brasil", mas a "antinação" (Motta, 1992, p.94 e ss.). Para eles, a moderna e dinâmica cidade de São Paulo seria destinada a liderar o país em direção a um futuro melhor. Muitos desses intelectuais, que se pronunciaram nos anos 1920 por meio da imprensa, viam a origem de todos os males do país na maneira pela qual a elite política tradicional teria transformado o Brasil numa cópia malfeita da Europa, sendo o Rio de Janeiro da Belle Époque o exemplo mais visível e detestável dessa obsessão por negar a si mesmo. Nessa perspectiva crítica, o objetivo de "reeuropeizar" o Brasil - utilizando um termo de Gilberto Freyre (Pallares-Burke; Burke, 2008, p.234-241) teria agravado ainda mais a situação de dependência cultural e econômica do país.

Além disso, o governo republicano estava em guerra com os novos atores políticos, como, por exemplo, os anarquistas e os comunistas, sendo que os últimos fundaram seu próprio partido em 1922. A ameaça mais séria, não obstante, se originou dentro do próprio Estado, mais precisamente no Exército. Dentro das Forças Armadas existiam, há muito tempo, grupos positivistas. Seus membros geralmente possuíam uma boa formação profissional, sobretudo em ciências naturais e engenharia. Alguns membros desses círculos positivistas estavam descontentes com a 'decadência' e a corrupção da República, e, por isso, decidiram transformar o Brasil em um país moderno por meio da força, ou seja, sob o comando de uma nova elite tecnocrática e esclarecida, embora não necessariamente democrática. Em julho de 1922, um pequeno grupo de oficiais jovens, com uma visão quase missionária, se rebelou no Forte de Copacabana com o propósito de derrubar o governo federal. O motim foi reprimido de maneira rápida e sangrenta. Esse acontecimento marcaria o começo de uma série de revoltas que, no contexto da grande depressão econômica de 1929, acabariam por dar fim ao que logo viria a ser chamado de República Velha.

É importante considerar essa situação de crise generalizada para poder contextualizar os debates sobre o sentido da história do Brasil que ocorreram nas comemorações da 
Independência. Essa tentativa da elite em apresentar a República Federal como o 'produto final' de um longo processo histórico linear pode ser explicada em grande parte pelos fortes questionamentos da legitimidade do sistema político. Decidida a renovar a legitimidade do sistema por meio da evocação dos 'momentos gloriosos' da história do republicanismo no Brasil, a elite republicana se baseou em elementos discursivos como o 'progresso', a 'civilização' e, sobretudo, a 'raça'. Embora o ideal do 'branqueamento' fosse muito mais antigo e já houvesse sido propagado e visualizado nas exposições do século XIX, para deter a temida 'africanização' do país por meio da imigração europeia, em 1922 o conteúdo dos debates sobre as supostas 'origens e qualidades raciais' do povo brasileiro havia mudado (Skidmore, 1976; Stepan, 1991; Schwarcz, 1993; Dávila, 2003; Hofbauer, 2006). A 'raça' ainda aparecia como fator fundamental para explicar o devir histórico, tal como havia sido formulado por Carl Friedrich Philipp von Martius em 1843. Martius ressaltou a influência das "três raças", ou seja, a branca, a vermelha e a negra, no processo de formação da nação brasileira, e exigiu, ao mesmo tempo, a criação de uma historiografia nacional brasileira, cujo fio condutor seria a "raça" (Hausser, 2009, p.169-198). Não obstante, ao contrário das exigências de Martius, cujas ideias de fato inspiraram boa parte da historiografia brasileira do século XIX, em 1922, a ideia da 'raça' como 'força histórica autônoma' já era vista com certo ceticismo por alguns participantes dos congressos e intelectuais.

Por um lado, havia pesquisadores e eruditos que ainda defendiam teorias na tradição do 'racismo científico' do século XIX, o qual tinha achado sua manifestação na nova ciência da eugenia, propagada com fervor desde 1918 pelo médico Renato Kehl, cujos seguidores se reuniam regularmente na Santa Casa de Misericórdia em São Paulo (Stepan, 1991; Diwan, 2007). Por outro lado, até no contexto bastante tradicional e conservador das celebrações oficiais do centenário, houve congressistas e intelectuais que rechaçaram qualquer conceito biológico de 'raça' e optaram por um novo enfoque, de cunho culturalista, ao explicar as causas históricas do relativo subdesenvolvimento do Brasil. De maneira geral, entretanto, a Exposição do Centenário se concentrou fortemente na higiene e divulgou campanhas contra a tuberculose e doenças venéreas com o propósito de 'cuidar da raça'. Nos congressos, participaram acadêmicos do mundo inteiro. Alguns deles estavam interessados no movimento internacional de eugenia, havendo, aliás, um pequeno grupo de intelectuais brasileiros inclinados a 'melhorar a raça' por meio de ações estatais.

A grande importância que a eugenia já tinha alcançado no contexto da Exposição do Centenário foi também exemplificada pela fundação da Liga Brasileira de Higiene Mental, em janeiro de 1923, no Rio de Janeiro, promovida pelo psiquiatra Gustavo Reidel. O objetivo declarado desse grupo, que a partir de 1925 contaria com a participação ativa de Renato Kehl, era a realização de um programa de profilaxia mental, focando nos 'deficientes' mentais e nos criminosos, os quais, na perspectiva dos eugenistas, teriam uma espécie de 'predeterminação hereditária' para cometer crimes. Esses "sujeitos", assim denominados por membros da liga, teriam de ser identificados, diagnosticados e até mesmo segregados, para o "bem de todos" (Stepan, 1991, p.51 e ss.; Reis, 2000). Porém, tais posições neolamarckistas eram bastante aceitas no começo dos anos 1920 não só no Brasil, mas no mundo inteiro (Kühl, 1997; Reis, 2000; Dávila, 2003). Assim, não parece estranho que só pouco tempo depois, em outubro de 
1923, alguns dos eugenistas mais destacados se reunissem novamente no Rio de Janeiro, nos moldes do Primeiro Congresso Brasileiro de Higiene (Congresso..., 1926).

No contexto das celebrações oficiais do centenário, as aspirações dos eugenistas se manifestaram de forma genuína no Dicionário histórico, geográfico e etnográfico do Brasil, que foi publicado por iniciativa governamental e sob a supervisão do Instituto Histórico e Geográfico Brasileiro com base no Decreto n. 15.066 do dia 24 de outubro de 1921. Esse decreto legislava também a organização da Exposição do Centenário, a inauguração do Panteão dos Andradas em Santos, assim como as inaugurações do novo Palácio do Conselho Municipal e do prédio completo da Escola Nacional de Belas Artes, no Rio de Janeiro. Com relação ao saneamento do país, no capítulo do Dicionário sobre higiene e saúde pública, o médico José Paranhos Fontenelle exigia que o governo tomasse todas as medidas cabíveis para tratar os habitantes doentes do interior do Brasil, pois a "degeneração gradual" daquela "raça de caboclos" dificultaria o progresso. Os esforços higienistas deveriam ser entendidos como uma luta por um "melhor tipo humano", o qual formaria a futura base da nacionalidade (IHGB, 1922b, p.457). Tais medidas também seriam necessárias para desfazer os efeitos malignos da importação de escravos africanos, pois eles trouxeram muitas doenças novas ao Brasil (p.418).

Para enfatizar sua posição, segundo a qual o "problema da raça" seria principalmente um problema de saúde pública, Fontenelle também fazia referência às novas possibilidades da eugenia, a qual seria a forma mais adequada para "cultivar a saúde física e mental do homem". Na opinião de Fontenelle, as últimas correntes do movimento higienista, como, por exemplo, a eugenia, a puericultura, a higiene pré-escolar e escolar, entre outras, representariam a realização do velho sonho do fundador do positivismo, Auguste Comte. Assim, os avanços da eugenia corrigiriam os erros do passado por meio da ciência "antropotécnica" prevista por Comte (IHGB, 1922b, p.446-447).

Tais discursos sobre a suposta 'degeneração' dos brasileiros pobres nas zonas rurais cumpriam a função de estigmatizar e excluir uma grande parte da população, propondo sua 'eugenização' gradual. Dessa maneira, negros, mulatos, indígenas e caboclos apareciam como os verdadeiros obstáculos do 'progresso', já que, historicamente, teriam impedido o desenvolvimento 'normal' do país, ou seja, um desenvolvimento segundo os padrões europeus ou norte-americanos. Na mesma obra, o eminente historiador, sociólogo e jurista Francisco José de Oliveira Viana expressou essa opinião de maneira ainda mais vigorosa. Tal como Martius em 1843, Oliveira Viana entendia que a miscigenação, que ocorria desde a época colonial, seria a principal característica da formação da nacionalidade brasileira. O resultado dessa miscigenação, porém, não o agradava. De modo extenso, ele descreveu como as qualidades inerentes das "três raças formadoras" supostamente teriam impedido o "progresso" do Brasil e como a "defeituosa raça portuguesa" teria contribuído para "retardar a civilização" (IHGB, 1922b, p.285 e ss.). No pensamento de Oliveira Viana, a única solução para o "problema racial" consistiria em acelerar o processo do "branqueamento" por meio da imigração europeia, privilegiando uma "colonização inteligente". Segundo Oliveira, no entanto, "valiosos elementos europeus" já teriam chegado ao Brasil desde os primeiros dias da Independência, como, por exemplo, os colonos alemães. Graças aos esforços de governos anteriores, essas "raças de boas qualidades" iriam garantir um futuro promissor ao Brasil: 
Por esses dados constatamos como é intenso o caldeamento da nossa gente com a gente nova e sadia, que aqui entra trazendo, na pureza ariana do seu sangue, a regeneração do nosso, abastardado pela fusão de sangues inferiores. O próprio alemão, que geralmente pressupomos dotado de uma certa infusibilidade, está, ao contrário, como se vê, fundindo-se largamente na massa da nossa população (IHGB, 1922b, p.283).

Para dar mais vigor a suas teorias, Oliveira Viana citava o escritor Monteiro Lobato, criador da popular figura do Jeca Tatu. Por meio dessa figura caricaturesca e amplamente difundida pela imprensa dos anos 1920, Monteiro Lobato tentava despertar a consciência pública acerca da suposta "degeneração" dos habitantes do inóspito interior do país (Dávila, 2003, p.29). Nesse sentido, o Jeca Tatu, cuja história também fora posta em cena no Palácio das Festas durante a exposição, servia como alegoria para demonstrar claramente que 'progresso' e 'civilização' somente seriam possíveis mediante campanhas de higiene e de maior penetração estatal nas regiões do interior, pois, nas palavras do médico Miguel Pereira, citado por José Paranhos Fontenelle no Dicionário, o interior do país ainda parecia um "vasto hospital", repleto de pessoas degeneradas e doentes (IHGB, 1922b, p.437). Diferentemente de Fontenelle, Pereira e outros higienistas, Oliveira Viana interpretava a degeneração dos caipiras não só como um problema de saúde, mas como o resultado de uma "má mistura racial". Devido a sua condição de "homem baldio, seminômade, inadaptável à civilização", o "Jeca Tatu" deveria ser um "mameluco", ou seja, o produto da miscigenação do europeu com o indígena, vivendo nas regiões fronteiriças do país (IHGB, 1922b, p.286).

Segundo o que foi difundido amplamente na grande imprensa na época, opiniões como as de Fontenelle e Oliveira Viana não eram nada incomuns em congressos e debates. Em 1922, o ideal do 'branqueamento' seguia então vigente, embora parecesse ter sido relegado a segundo plano pela maioria dos jornalistas, que se interessavam mais pelos problemas políticos e econômicos do país. Indígenas e africanos foram descartados como sujeitos da história pelos historiadores, antropólogos e arqueólogos reunidos no Rio de Janeiro em 1922, e suas culturas e história também não ocuparam lugar importante nas salas da Exposição do Centenário. Ao contrário de exposições anteriores, incluindo a Exposição Nacional de 1908, cujos organizadores se atreveram a mostrar figuras indígenas de tamanho natural em seu suposto 'habitat selvagem', a população idealizada de 1922 consistia quase que exclusivamente de brasileiros europeizados e brancos. Esse suposto 'tipo brasileiro' foi ilustrado por meio de quadros, cartazes, publicidades, fotografias e até mesmo filmes.

Nas atas dos congressos de historiadores e americanistas, entretanto, ainda se acham alguns dos velhos discursos sobre o 'selvagem nobre', símbolo nacional do Império, ou sobre o escravo negro, retirado da África 'para seu próprio bem' e 'levado para junto da civilização'. Um exemplo típico dessa interpretação historiográfica, segundo a qual os africanos teriam sido levados ao Brasil para serem 'salvos e civilizados' na tradição da ideologia do 'resgate' jesuítico, nos ofereceu o conferencista Roberto de Miranda Jordão:

A nossa escravidão não era, porém, obtida diretamente na guerra e sim de um modo indireto: os traficantes de escravos compravam os prisioneiros dos chefes negros, que os tinham vencido, de sorte que eles mudavam vantajosamente de senhor, pois os nossos eram incomparavelmente mais adiantados em civilização, que os da África, de quem os escravos eram, além disso, inimigos, prisioneiros de guerra (IHGB, 1927, p.884). 
Embora a maioria das opiniões acadêmicas sobre o significado do 'elemento africano' na formação da nação fosse negativa e condenatória, também houve palestrantes que reconheceram certa contribuição histórica da 'raça negra'. Assim, por exemplo, o renomado jurista, político e historiador Afonso Cláudio, ao indagar sobre as contribuições históricas de cada uma das 'três raças formadoras', formulou algumas ideias já bastante parecidas com o porvindouro conceito da 'democracia racial' de Gilberto Freyre. Embora Cláudio tivesse estabelecido uma clara hierarquia entre portugueses, indígenas e africanos, pelo menos atribuía certos valores culturais e econômicos aos últimos, e, especialmente, à mulher africana como portadora de práticas culturais e comportamentos tipicamente brasileiros (IHGB, 1927, p.356). De todas as maneiras, Cláudio, tal como os demais conferencistas preocupados com o 'problema racial', estava longe de assumir uma posição 'antirracista'. Em sua opinião, o "elemento negro" era pelo menos tão defeituoso como o "elemento indígena", cuja contribuição ao "caráter nacional" teria sido igualmente "negativa e nociva" (IHGB, 1927, p.360 e ss.).

Defendendo as teorias poligenistas de Louis Agassiz e Gustave Le Bon, Cláudio apoiava a imigração maciça de europeus brancos para acelerar o desaparecimento das "raças nativas" (IHGB, 1927, p.345; 354). Assim, ele e muitos de seus colegas viam no processo da miscigenação a chave para assegurar o 'futuro racial' do país. Contrariando teorias mais antigas sobre a suposta degeneração biológica causada por qualquer tipo de mistura racial, Cláudio ressaltava os efeitos positivos da miscigenação em países de populações tão heterogêneas como Canadá, Austrália e, sobretudo, Estados Unidos. Essas sociedades, formadas pela imigração maciça, se destacariam por seu alto nível de 'civilização' e sua excelente governabilidade. Diferentemente da maior parte dos defensores da imigração europeia, Cláudio criticava, contudo, a obsessão de alguns políticos por fomentar exclusivamente a entrada de supostas "raças puras" ou "arianas". A recente guerra mundial não teria mostrado que essas "raças" não eram tão "puras" nem necessariamente tão "civilizadas"? A inadaptabilidade dos alemães "militaristas e servis" não comprovaria a falsidade de tais concepções? (IHGB, 1927, p.368-369).

O ideal do 'branqueamento', apresentado repetidamente como 'programa antirracista' por acadêmicos e intelectuais, foi então uma figura legitimadora frequente em várias publicações que saíram no contexto das celebrações do centenário. O objetivo dessas publicações - como fica evidenciado na monumental obra Geografia do Brasil² - era a paulatina 'desafricanização' do país, pois sem africanos não haveria racismo. Essa era a lógica crua dos supostos 'antirracistas' da Sociedade Geográfica do Rio de Janeiro. Para evitar a experiência de um racismo extremo e violento, como aquele que se manifestava no sul dos Estados Unidos depois da guerra civil, deveria ser eliminado o 'elemento negro'. Desse modo, o racismo não ocorreria no Brasil: "em todo o Brasil não há a odiosa separação racial entre brancos e negros, como acontece na América do Norte, chegou-se à realidade da formação de um poderoso amálgama étnico" (SGRJ, 1923, p.217).

Em geral, tais comparações entre o Brasil e os Estados Unidos eram abundantes nos congressos de história, antropologia e arqueologia, como, por exemplo, a feita pela historiadora norte-americana Mary Wilhelmine Williams, que comparava os sistemas escravistas das duas sociedades. Essas palestras acabavam quase sempre em velhos preconceitos e estereótipos. Assim, a historiadora chegou à conclusão nada surpreendente de que os escravos brasileiros 
não só teriam sido tratados de maneira mais 'humana', mas que teriam contribuído para o nascimento de uma sociedade igualitária. Na perspectiva 'cientificamente' legitimada do antigo conceito do Brasil como 'paraíso racial', originalmente formulado por abolicionistas norte-americanos na primeira metade do século XIX, a miscigenação entre negros e brancos teria transformado o Brasil numa sociedade livre de racismo, ao contrário do ocorrido nos Estados Unidos: "No Brasil, eles [os negros] tinham todos os direitos dos homens brancos. Nunca houve discriminação de cor, o que fazia com que o Brasil fosse, como dizia uma mulher branca do Sul dos Estados Unidos, 'o verdadeiro paraíso dos negros'” (IHGB, 1922a, p.291; destaque no original) ${ }^{3}$

Interpretações como essa, que reconheciam certas contribuições do 'elemento servil' dos negros no processo de formação da nação, embora negassem a capacidade de 'ambas as raças' para promover uma mudança histórica, eram bastante frequentes no contexto do centenário. Embora os bairros pobres do Rio de Janeiro fossem habitados basicamente por negros e pardos empobrecidos e excluídos, a dura realidade desses grupos sociais não era representada nos congressos nem nas salas de exposição. Quando muito, as elites políticas e culturais reconheciam dentro de debates acadêmicos as supostas "deficiências raciais" do povo brasileiro, mas se negavam decididamente a apresentar o "deplorável status quo" aos olhos do mundo (Tenorio-Trillo, 1998, p.286, 292). Como o sentido das exposições não consistia em refletir a realidade deficiente, mas em definir o que ia ser a nação do futuro, o Brasil teria que se mostrar como o que ainda não era: um país branco, europeizado, industrializado e democrático.

Os discursos sobre 'progresso', 'civilização' e 'raça' não se limitavam, por conseguinte, à esfera simbólica. Durante as obras de construção dos pavilhões da Exposição do Centenário, o governo decidiu destruir o morro do Castelo. Esse morro se encontrava no coração do Rio de Janeiro, e seu espaço deveria servir para a construção de alguns prédios da exposição. Além disso, em cima dele havia numerosas moradias precárias e cortiços, além de duas igrejas da época colonial. Nesse contexto, os políticos e planejadores urbanos ao redor do prefeito Carlos Sampaio (1920-1922) lançaram uma campanha publicitária para extirpar esse "dente putrefato", aquela "verruga monstruosa" que supostamente enfearia o bonito rosto da "cidade maravilhosa" (Sampaio, 1925, p.5; A Noite, 6 ago. 1920).

Na perspectiva das elites, teria sido uma grande vergonha se os visitantes internacionais da exposição tivessem visto esse aspecto tão pouco apresentável da realidade carioca. Embora o plano do governo encontrasse certa oposição na imprensa e nos círculos intelectuais da capital, como nas colunas do escritor mulato Lima Barreto (30 set. 1922), a destruição do morro do Castelo foi posta em prática. Seus habitantes pobres foram expulsos sem piedade (Motta, 1992; Meade, 1997; Rezende, 2008). A estratégia do governo foi bem-sucedida. Assim como o intelectual mexicano José Vasconcelos, um dos visitantes mais famosos da exposição, quase todos os estrangeiros descreveram o lugar que viram durante sua estadia como a 'cidade maravilhosa' dos cartões-postais. Em poucos documentos ou cartas dos delegados estrangeiros se acham referências aos cortiços, à desigualdade social ou ao racismo sutil da sociedade carioca (Tenorio-Trillo, 1994). José Vasconcelos, ministro da educação em seu país, foi o encarregado da apresentação mexicana na exposição e se deixou enganar pela fachada erguida pelo governo brasileiro (Tenorio-Trillo, 1994). A ideia de um país cuja história estaria 
baseada na 'harmoniosa mistura das raças' e no qual não se conhecia o racismo viria inclusive a inspirar seu mais famoso livro, La raza cósmica (1925). Segundo Mauricio Tenorio-Trillo (1994, p.137 e ss.), Vasconcelos viu, ou melhor, queria ver no Rio de Janeiro uma espécie de melting pot, o qual representaria o contramodelo latino-americano frente às supostas "raças puras anglo-saxãs", cuja decadência lhe parecia inevitável.

A glorificação das 'raças ibéricas', assim como a celebração das suas epopeias históricas, foi outro elemento central da (re-)construção da história nacional pelos centenaristas não só no Brasil, mas em toda a América Latina. No contexto das exposições universais, o 'hispanismo' e o 'lusitanismo' das primeiras décadas do século XX culminariam finalmente na Exposição Ibero-americana de Sevilha, em 1929. No Brasil, a revalorização do papel histórico de Portugal e sua 'raça heroica' de descobridores e colonizadores pode ser percebida já na Exposição Nacional de 1908, na qual se celebrou não só o 'primeiro passo' para a independência, mas também a herança colonial lusa, a qual tinha sido rechaçada durante quase um século. A revalorização das tradições portuguesas não só foi refletida em numerosas crônicas e ensaios apresentados nos congressos do centenário, os quais em geral buscavam estabelecer um vínculo comum com a 'raça ibérica', mas também na arquitetura da exposição. Assim, por exemplo, vários dos pavilhões emblemáticos foram construídos em estilo neocolonial. A mostra mais impressionante da revalorização da tradição portuguesa foi o pavilhão das indústrias da Exposição do Centenário, destinado a ser a sede do futuro Museu Histórico Nacional. Apesar de ter sido concebido pela elite política e cultural como um importante lugar de memória, cujo fim declarado seria a preservação da memória histórica da Colônia e do Império, o suposto 'estilo colonial' do prédio foi na verdade uma mistura eclética de vários estilos de diferentes épocas. Como destaca Daryle Williams, esse e outros prédios dos anos 1920 e 1930 eram o resultado de uma mistura de vários estilos coloniais ibero-americanos, assim como o chamado California Mission Revival Style, que tivera sua origem na última década do século XIX nos Estados Unidos e que teria influenciado os arquitetos brasileiros por meio de filmes de Hollywood e revistas norte-americanas (Williams, 2001; Rezende, 2008). Entretanto, o mais importante era estabelecer um vínculo simbólico com uma 'época de ouro', embora aplicando os métodos e a tecnologia de um presente não tão 'dourado'.

\section{Vozes críticas?}

Como já mencionado, a versão oficial da história do Brasil, construída pela elite política e cultural no contexto da Exposição do Centenário, foi contestada por alguns intelectuais e comentaristas críticos na imprensa. Grande parte dessas vozes críticas, no entanto, era superficial e não questionava as premissas centrais da interpretação oficial da história, ou seja, os conceitos relacionados a 'progresso', 'civilização' e 'raça'. Sobretudo as críticas provindas de São Paulo e Minas Gerais, que enfocavam meramente aspectos regionalistas e sublinhavam as ações daqueles nascidos nessas regiões. Os historiadores e comentaristas paulistas, por exemplo, apresentavam a história do Brasil como um processo cuja dinâmica residia no agir de "aventureiros bravos e fisicamente robustos", na sua maior parte caboclos ou brancos (SGRJ, 1923, p.222). Enquanto as elites cariocas celebravam os conquistadores portugueses como fundadores da nação, as elites paulistas e mineiras faziam o mesmo com os lendários 
bandeirantes, uma verdadeira "raça de gigantes", segundo o botânico francês Auguste SaintHilaire, citado por Oliveira Viana (IHGB, 1922b, p.290).

Enquanto as poucas críticas da parte dos historiadores eram bem mais superficiais e geralmente motivadas pela política, alguns dos antropólogos e arqueólogos reunidos no Congresso Internacional de Americanistas denunciaram com mais veemência a historiografia oficialista. Seu enfoque estava nos povos indígenas do Brasil, cujo lugar na história teria sido injustamente negado desde o advento da República, segundo alguns dos participantes. Embora a figura do indígena tivesse ocupado um lugar importante na iconografia do Império, sua possível contribuição à formação da nação teria sido silenciada e reprimida no contexto da comemoração do centenário. Nesse sentido e devido ao enfoque culturalista da nova corrente da antropologia inspirada na obra do germano-norte-americano Franz Boas, alguns dos participantes do Congresso de Americanistas tentaram revalorizar as etnias indígenas do Brasil e trataram de definir seu lugar na história nacional. Salvo poucas exceções, criaram novamente a imagem indianista do 'bom selvagem' no sentido de Rousseau, segundo a qual o indígena teria contribuído para a formação da nação brasileira com seu 'heroísmo'.

Ao contrário do que afirmava o indianismo das décadas anteriores, a 'mentalidade heroica' do indígena já não resultaria de sua 'raça', ou seja, de uma predisposição genética, mas de sua evolução cultural. De acordo com novas pesquisas antropológicas, os indígenas brasileiros já não poderiam ser classificados por meio de categorias biológicas, baseadas, por exemplo, na estrutura do crânio para deduzir certas mentalidades ou seu nível de inteligência, mas por seus hábitos, seu sistema de normas e sua língua. Alguns antropólogos, como, por exemplo, Francolino Camêu, chegaram a denunciar com fervor a destruição consciente dos povos indígenas iniciada na época colonial (Clerot, Brandão, 1928, p.371). No entanto, algumas linhas mais adiante, o próprio Camêu insinuou que os indígenas, embora "incultos e ignorantes", seriam "remediáveis" por meio da missão católica, negando assim o valor autônomo de suas culturas (p.378). Segundo Camêu, por outro lado, os africanos, "criaturas embrutecidas", nem sequer teriam essa opção (p.379). A maior parte dos participantes do Congresso de Americanistas reconhecia os avanços da antropologia, mas, ao mesmo tempo, continuava classificando e hierarquizando as etnias indígenas segundo suas supostas 'qualidades raciais' e seu nível de 'civilização'. Quase todos concordavam com a hipótese amplamente difundida no centenário de que a "raça indígena" estaria destinada a desaparecer, como sustentou, por exemplo, Elísio de Carvalho em Origens da sociedade brasileira (Clerot, Brandão, 1928, p.279 e ss.). O interesse principal desse autor consistia, no entanto, em comprovar a "nobreza do sangue" do povo brasileiro da época. Incomodado pelos preconceitos europeus sobre a presumida "decadência racial" dos brasileiros, Carvalho explicava de maneira extensa por que a "raça brasileira" teria sido "purificada" com o passar do tempo: devido à constante importação de "sangue europeu nobre", os "defeitos raciais" dos indígenas teriam desaparecido gradualmente (p.281).

Em todos esses casos, os índios e sua cultura só serviam de pretexto para traçar linhas de continuidade entre um passado glorioso, embora 'morto', e um presente não menos glorioso. Poucos participantes desses congressos se interessavam realmente pelos índios reais e vivos e também não criticavam as políticas indigenistas dos últimos cem anos e suas consequências nefastas. Do mesmo modo que na época do indianismo romântico do século 
XIX, o novo 'indianismo científico' dos anos 1920 se aproximava de seu 'objeto de pesquisa' de maneira instrumentalista e pessimista. O potencial crítico desses textos e comentários, os quais descreviam o indígena brasileiro como objeto e não como sujeito da história, ficou, por conseguinte, bastante limitado.

Apesar da negação da maior parte dos historiadores, antropólogos e jornalistas em atacar de maneira direta as políticas da história do regime republicano, a visão oficialista da história nacional foi contestada, surpreendentemente, pela esfera artística, com contundentes críticas. Quase dois anos antes da inauguração da Exposição do Centenário, os jovens modernistas, majoritariamente radicados em São Paulo, já tinham formulado propostas 'revolucionárias' sobre o que deveria ser, segundo eles, a nação brasileira. De maneira geral, os adeptos do modernismo criticavam a imitação superficial de modelos estrangeiros, não só na esfera política e econômica, mas, sobretudo, na arte, na arquitetura e na literatura. Embora formassem um grupo bastante heterogêneo, os modernistas tinham como denominador comum a resistência à 'reeuropeização' do país.

Ainda mais interessante resulta o fato de as suas posições mostrarem, frequentemente, uma dimensão histórica. Segundo o escritor Oswald de Andrade, um dos participantes mais prolíficos da hoje lendária Semana de Arte Moderna, que teve lugar entre os dias 13 e 17 de fevereiro de 1922, em São Paulo, era necessário incorporar certos modelos culturais europeus e norte-americanos, mas só para criar algo autêntico, e não para imitá-los. Só dessa maneira o Brasil conseguiria a verdadeira independência. São Paulo, devido à valiosa 'raça' de seus habitantes - produto das bandeiras e da subsequente mistura entre "o melhor do sangue indígena e ibérico" - seria então o único lugar adequado para celebrar o centenário: "São Paulo, a melhor fatia racial a expor na vitrine do Centenário, tem a decidir o que dará em matéria de arte ... Senhores, é isso que vamos apresentar como expressão de cem anos de independência: independência" (Andrade, 16 maio 1920).

A noção de uma arte híbrida e 'verdadeiramente brasileira', uma arte que celebrava a brasilidade e, ao mesmo tempo, rechaçava o legado colonial consagrado pela elite tradicional na Exposição do Centenário, teve um impacto profundo na história cultural do Brasil. Depois de 1922, todos os artistas 'verdadeiramente brasileiros' teriam de reconhecer e continuar as premissas dos modernistas. No contexto de rebeldia contra o establishment, a Semana de Arte Moderna apresentava ao público obras que frequentemente faziam referência explícita às culturas afro-brasileiras e indígenas. Nunca antes foram apresentadas essas 'raças' decididamente 'não europeias' como parte integral da formação da nação brasileira num evento público de semelhante impacto midiático (Boaventura, 2001; Gonçalves, 2012).

\section{Considerações finais}

Em conclusão, pode-se constatar que as celebrações do centenário em 1922 e, principalmente, a Exposição do Centenário representam um importante marco na história brasileira, no qual uma significativa mudança pode ser percebida. Como reflexo da crise política daqueles anos, a análise dos debates e conferências sobre o sentido da história do Brasil e sobre possíveis novas interpretações dessa história é bastante reveladora. Embora os eventos oficiais no Rio de Janeiro tenham sido obra da elite política e cultural que geralmente 
tendia a celebrar a si mesma e seus próprios antepassados, alguns comentários na imprensa, assim como algumas palestras nos congressos, deixam entrever as mudanças discursivas que iam se esboçando nos anos 1920. O eixo temático fundamental de toda a historiografia nacional desde meados do século XIX fora o conceito das 'três raças formadoras' criado por Martius e outros intelectuais. A ideia de conceber o processo histórico do Brasil como produto da miscigenação e de atribuir à 'raça' uma força autônoma como agente dinâmico nesse processo se mostrou ainda em voga em 1922. Alguns exemplos, todavia, demonstram como o discurso racial estava se transformando, passando de uma abordagem biológica a uma mais culturalista. Assim, por exemplo, ganhou terreno o ideal da 'raça cósmica', proposto por Vasconcelos, que se transformaria em ideologia oficial a partir dos anos 1930 sob a forma da 'democracia racial'. Do mesmo modo que o discurso da mestizaje no México de Vasconcelos, a 'democracia racial' brasileira incorporaria elementos da cultura popular e seria elevada ao patamar de ideologia nacional por Getúlio Vargas. Não obstante, a prevalência desse novo discurso continuaria encobrindo durante décadas o racismo existente e a exclusão social de grande parte da população.

Além do mais, a comemoração do centenário representa um hiato histórico, pois era o último instante de autoconfiança e relativa estabilidade de um sistema político em crise. Em 1922, as diferentes vozes críticas ainda não chegaram a formar um discurso homogêneo, mas sua mera existência já indicava o aparecimento de novos setores da sociedade, os quais não só exigiram mudanças políticas e econômicas, mas também uma nova forma de interpretar a história nacional. É por isso que a Semana de Arte Moderna, embora só tenha durado poucos dias, ocupa até hoje um lugar de destaque na memória coletiva, se fazendo presente em canções, livros e exposições (Gonçalves, 2012), enquanto a celebração oficialista do centenário está praticamente esquecida.

\section{NOTAS}

\footnotetext{
${ }^{1}$ Este ensaio é parte de um projeto mais amplo, no qual são analisados os jornais e revistas mais importantes da grande imprensa carioca. Comentários diretamente relacionados às diferentes interpretações do passado no contexto da comemoração da Independência se acham em A Noite, A Careta, Correio da Manhã, Jornal do Commercio, Jornal do Brasil, Gazeta de Notícias, Revista da Semana e O Paiz.

${ }^{2}$ Os planos para essa obra eram 'monumentais'. E, no final, dos dez tomos previstos originalmente, só foram publicados os de número 1, 2, 9 e 10.

${ }^{3}$ Nessa e nas demais citações de textos publicados em outros idiomas, a tradução é livre.
}

\section{REFERÊNCIAS}

ANDRADE, Oswald de.

Arte do centenario. Jornal do Commercio, Rio de Janeiro. 16 maio 1920.

\section{A NOITE.}

É um verdadeiro attentado o arrazamento do morro do Castello! A Noite, Rio de Janeiro, n.3.160, p.1. 6 ago. 1920.

BARRETO, Afonso Henriques de Lima.

O Centenario. A Careta, Rio de Janeiro, n.745, p.24. 30 set. 1922 .
BENCHIMOL, Jaime Larry.

Pereira Passos: um Haussmann tropical: a renovação urbana da cidade do Rio de Janeiro no início do século XX. Rio de Janeiro: Secretaria Municipal de Cultura, Turismo e Esportes; Departamento Geral de Documentação e Informação Cultural; Divisão de Editoração. 1990.

BOAVENTURA, Maria Eugenia (Org.)

22 por 22: a Semana de Arte Moderna vista pelos seus contemporâneos. São Paulo: Edusp. 2001. 
CLEROT, Léon; BRANDÃO, Paulo José Pires (Ed.). Congresso Internacional de Americanistas, 20., 20-30 ago. 1922, Rio de Janeiro. Annaes... Rio de Janeiro: Imprensa Nacional. v.2. 1928.

\section{CONGRESSO..}

Congresso Brasileiro de Hygiene, 1., out. 1923, Rio de Janeiro. Annaes... Rio de Janeiro: Oficinas Gráficas da Inspetoria de Demografia Sanitária. v.1. 1926.

DÁVILA, Jerry.

Diploma of whiteness: race and social policy in Brazil, 1917-1945. Durham: Duke University Press. 2003.

DIWAN, Pietra. Raça pura: uma história da eugenia no Brasil e no mundo. São Paulo: Contexto. 2007.

GONÇALVES, Marcos Augusto.

1922: a semana que não terminou. São Paulo: Companhia das Letras. 2012.

HAUSSER, Christian.

Auf dem Weg der Zivilisation: Geschichte und Konzepte gesellschaftlicher Entwicklung in Brasilien (1808-1871). Stuttgart: Steiner. 2009.

HOFBAUER, Andreas.

Uma história de branqueamento ou o negro em questão. São Paulo: Unesp. 2006.

IHGB.

Instituto Historico e Geographico Brasileiro (Ed.). Congresso Internacional de História da América, 1., 7-15 set. 1922, Rio de Janeiro. Annaes... Rio de Janeiro: Imprensa Nacional. v.3. 1927.

IHGB.

Instituto Historico e Geographico Brasileiro (Ed.). Congresso Internacional de História da América, 1., 7-15 set. 1922, Rio de Janeiro. Annaes... Rio de Janeiro: Imprensa Nacional. v.1. 1922a.

IHGB.

Instituto Historico e Geographico Brasileiro (Ed.). Diccionario historico, geographico e ethnographico do Brasil. Rio de Janeiro: Imprensa Nacional. v.1. 1922b.

KÜHL, Stefan.

Die Internationale der Rassisten: Aufstieg und Niedergang der internationalen Bewegung für Eugenik und Rassenhygiene im 20. Jahrhundert. Frankfurt am Main: Campus. 1997.

MEADE, Teresa.

"Civilizing" Rio: reform and resistance in a Brazilian city, 1889-1930. University Park: The Pennsylvania State University Press. 1997.

MOTTA, Marly Silva da.

A nação faz 100 anos: a questão nacional no
Centenário da Independência. Rio de Janeiro: Editora da FGV. 1992.

PALLARES-BURKE, Maria Lúcia; BURKE, Peter. Repensando os trópicos: um retrato intelectual de Gilberto Freyre. São Paulo: Editora Unesp. 2008.

REIS, José Roberto Franco.

"De pequenino é que se torce o pepino": a infância nos programas eugênicos da Liga Brasileira de Higiene Mental. História, Ciências, Saúde - Manguinhos, Rio de Janeiro, v.7, n.1, p. 135-157. 2000.

REZENDE, Thaís da Silva de Sant'Ana. A Exposição Internacional do Centenário da Independência: modernidade e política no Rio de Janeiro do início dos anos 1920. Tese (Mestrado) - Instituto de Filosofia e Ciências Humanas, Universidade Estadual de Campinas, Campinas. 2008.

SAMPAIO, Carlos.

O arrasamento do morro do Castelo. Rio de Janeiro: Typographia da Gazeta da Bolsa. 1925.

SCHWARCZ, Lilia Moritz.

O espetáculo das raças: cientistas, instituições e questão racial no Brasil. São Paulo: Companhia das Letras. 1993.

SGRJ.

Sociedade de Geographia do Rio de Janeiro (Org.). Geographia do Brasil: commemorativa do $1^{\circ}$ centenario da Independencia, 1822-1922. Rio de Janeiro: Pimenta de Mello. v.10. 1923.

SKIDMORE, Thomas E.

Preto no branco: raça e nacionalidade no pensamento brasileiro. Rio de Janeiro: Paz e Terra. 1976.

STEPAN, Nancy Leys.

"The hour of eugenics": race, gender, and nation in Latin America. Ithaca: Cornell University Press. 1991.

TENORIO-TRILLO, Mauricio.

Artilugio de la nación moderna: México en las exposiciones universales, 1880-1930.

México: Fondo de Cultura Económica. 1998.

TENORIO-TRILLO, Mauricio.

Um Cuauhtémoc carioca: comemorando o Centenário da Independência do Brasil e a raça cósmica. Estudos Históricos, Rio de Janeiro, v.7, n.14, p.123-148. 1994.

WILLIAMS, Daryle. Culture wars in Brazil: the first Vargas regime, 1930-1945. Durham: Duke University Press. 2001. 